\title{
International Technology Mergers \& Acquisitions and Raising the Competitiveness of China Equipment Manufacturing Industry ${ }^{*}$
}

\author{
Xiuling Liu, Li Cai, Huiping Tan \\ International Business School, Dalian Nationalities University, Dalian, China \\ Email: caili@dlnu.edu.cn, lucy1990@126.com, huiping.tan@yahoo.com.cn
}

Received October 27, 2011; revised November 27, 2011; accepted December 5, 2011

\begin{abstract}
Developing and strengthening the competitiveness of the equipment manufacturing industry is that needs solving the weighty problem. China equipment manufacturing enterprises could acquire the core technique with international technology mergers \& acquisitions. This is an important strategy that could facilitate raising innovation capital and R \& D level of the enterprise by a wide margin. This paper analyses the problems of China equipment manufacturing industry, advantages of international technology mergers \& acquisitions and puts forward appropriate proposals and measures.
\end{abstract}

Keywords: International Technology Mergers \& Acquisitions; Equipment Manufacturing Industry; Competitiveness

\section{Introduction}

Equipment manufacturing industry is a general term of companies which provide high technology equipment for the development of national economy and security, covering all of the enterprises in machinery, electronics, weapons and ammunition manufacturing. In this industry, the products include systems, hosts, parts and components, and technical services as well. Equipment manufacturing industry is a basic and strategic industry, reflecting the comprehensive national strength, technological strength and international competitiveness of a country. Besides, it determines the role of a country in the world. Many countries regard equipment manufacturing industry as their leading industry in the stage of mature industrialization.

With the development of the past 60 years, China equipment manufacturing industry has had an industrial system with complete ranges and large scale. However, compared with developed industrialized countries, China equipment manufacturing industry is still backward, and it does not comply with the development of the national economy of China [1].

Taking machinery manufacturing industry as an example, the labor productivity in 2007 was RMB 143,000/ person/year (up 386.6\% from 1999), but it was only equivalent to one fifth of the United States in 1995, one third

\footnotetext{
*This research was supported by College Research Project (Social Science) of Education Department of Liaoning Province (2009A149) and National Social Science Foundation of China (11BMZ043).
}

of Germany in 1996, one sixth of Japan, one fifth of the United Kingdom and the half of South Korea [2]. In 2007, the sales profit margin of China machinery manufacturing industry was $6.2 \%$, while that of the developed countries was in the range $13 \%-20 \%$.

Chinese equipment manufacturing industry has always depended on the introduced technology. According to China Machinery Industry Federation, 57\% of the industrialization of products in China machinery manufacturing industry was finished on the basis of imported technology in 2005 [3]. There are few Chinese products with independent intellectual property rights or strong international competitiveness in the industry; lots of the core technology and key products are imported from the foreign countries. For example, China ranked the first in the output value of machine tool industry in the world in 2009 as the world's largest consumer; however, it was also the largest importer in the world, and the high-end CNC machine tools account for the large part of importing machine tools.

It is urgent to find out how to quickly improve the technology of China equipment manufacturing industry, explore and strengthen the core competitiveness of the industry. Chinese enterprises can gain the core technology through international technology merger \& acquisition (short for "M \& A"), and then they may integrate, digest and absorb the technology to promote their own innovation and R \& D abilities, as well as improve their core competitiveness greatly. 


\section{Advantages of International Technology Merger \& Acquisition}

International merger \& acquisition includes international merger and international acquisition. International merger means that two different enterprises in two different countries are combined into a new legal entity or merge into an existing enterprise [4]. International acquisition means that a company in a country purchases the entire assets or overwhelming shares of another company in another country through certain channels and payment methods for some purposes.

International technology M \& A take place when the international merger \& acquisition happen for technical purposes. International technology M \& A includes Horizontal M \& A, Vertical M \& A and Joint M \& A.

From the perspective of the access to technology, Horizontal $\mathrm{M} \& \mathrm{~A}$ is the international merger \& acquisition for the access to the technology used in main business. Usually, the main business technology is the core technology of companies. If the main business technology is in charge of others, not only R \& D and design of China equipment manufacturing industry are controlled by others, but also China equipment manufacturing industry is confronted with a survival crisis in the global market, because technology is one of factors which have huge market monopoly power. If Chinese equipment ma- nufacturing companies acquire or merge overseas enterprises to mater key technology, they will lay a good base for the future development. Horizontal M \& A could be the first choice for Chinese equipment manufacturing industry to acquire or merge overseas enterprises.

Vertical M \& A is the international merger \& acquisition for the access to the upstream and downstream technology related with main business. The achievement of upstream technology can help companies to save transaction costs; the achievement of downstream technology benefits them to develop new products and new technology. Vertical M \& A technology will facilitate the international integration of operation for companies. For the equipment manufacturing enterprises located in the old industrial bases in northeast of China, Vertical M \& A will enable them to make full use of technical resources and products supporting advantages of these old industrial bases.

Joint M \& A is the international merger \& acquisition for the access to the technology unrelated with main business. For the further development, a large enterprise wishes to enter a wholly-new industry or a technology-based industry unrelated with the current business; in this case, it can adopt Joint $M$ \& A to realize this goal. By Joint M \& A, the enterprise can take over the target company together with its technology, market, personnel and organizational management, so that it can break through technical barriers to enter new fields easily and soundly. In addition, through the injection and transfer of resources, the enterprise can also turn the acquired technology-based company into an alternative enterprise for new future in order to focus on new technology-based field instead of the original field. The achievement of unrelated technology is inspired by the corporate diversification strategy. However, with the intensified global competition and the accelerated development of technology, most of enterprises would rather pay more attention to their core business than enter a new industry unrelated with the core business through acquisition [5]. Now, there is no suitable environment for the implementation of Joint M \& A in China.

Compared with other methods of access to high technology, the superiority of international technology M \& A is mainly reflected in technology real-time service effect and technology innovation promoting effect.

\subsection{Technology Real-Time Service Effect}

Technology real-time service effect means the technology gained by enterprises via international M \& A can be applied immediately, absorbed and used in their production and management systems quickly, which enhances the technology level and competitiveness of enterprises rapidly. Among the methods of access to technology, only international technology M \& A has technology realtime service effect.

Although companies can get the desired technology through joint $\mathrm{R} \& \mathrm{D}$, joint ventures and technology alliances, they can not use the technology quickly. Enterprises can also obtain the desired technology by technology licensing and technology purchasing swiftly, however these one-way modes are often companied with information asymmetry, so they can not absorb and digest the technology effectively. Obviously, the efficiency of technology licensing and technology purchasing is lower than that of international technology M \& A. The technical elements achieved by $\mathrm{M} \& \mathrm{~A}$ should be combined with the original technical elements of enterprises to facilitate the emergence of technology real-time service effect rapidly, which will improve the competitiveness of these enterprises.

\subsection{Technology Innovation Promoting Effect}

Companies can polish their original technology or develop new technology after $\mathrm{M} \& \mathrm{~A}$, so as to improve their technological innovation abilities. International technology M \& A not only help enterprises to save R \& D costs, but also encourage them to develop technology. For example, DuPont Company was the largest gunpowder company in the United States at beginning of the 20th century. After 1920s, it acquired more than 100 enterprises in the chemical industry to grasp diversified 
chemical production technology. Then, it established several divisions for dye, fiber and plastics. After the World War II, DuPont re-innovated the technology acquired by the international technology $\mathrm{M} \& \mathrm{~A}$ and made technological achievements hereby. With these achievements, it occupied a dominating position in macromolecule field firmly.

\section{Recommendations for Improving Core Competitiveness of China Equipment Manufacturing Industry by International Technology Merger \& Acquisition}

It is urgent to find out how to quickly improve the technology of China equipment manufacturing industry, explore and strengthen the competitiveness of the industry. It is a fundamental way to resolve the problem by improving the independent innovation capability of enterprises. Chinese enterprises can gain the core technology through international technology $\mathrm{M} \& \mathrm{~A}$, and then they may integrate, digest and absorb the technology to promote their own innovation and R \& D abilities. International technology $\mathrm{M} \& \mathrm{~A}$ is very risky, however it is a direct and effective way for access to high technology, because the time cost is higher than the economic cost.

In October 2004, Shenyang Machine Tool Group of China acquired the world's best machine tool company SCHIESS AG of Germany. SCHIESS becomes one of three major manufacturing clusters and an overseas R \& D base of Shenyang Machine Tool Group. After the acquirement, Shenyang Machine Tool Group possesses an international machine tool brand, large-scale machine tool production technology, and an overseas production and R \& D base. Currently, SCHIESS' technology has been applied by Kunming Machine Tool Company of Shenyang Machine Tool Group, and the products made by the technology have been sold to China Erzhong Group, Taiyuan Heavy Machinery Group Co., Ltd, Dongfang Steam Turbine Co., Ltd, Hudong Heavy Machinery Co., Ltd and other key China equipment manufacturing enterprises.

In 2002, Dalian Machine Tool Group acquired Production System Corporation of Ingersoll Machine Tools, Inc. of the United States. Ingersoll is a leader in special machine tools and flexible manufacturing system technology in the world. This acquirement was a historic breakthrough in China machine tool industry. Later, Dalian Machine Tool Group acquired and controlled Crankshaft Machining System Corporation of Ingersoll Machine Tools, Inc. and F. Zimmermann GmbH of Germany. After the acquirement, Dalian Machine Tool Group held 96 proprietary technologies, 9 patents, trademarks and other intangible assets of Ingersoll as well as the technology strength of Ingersoll and Zimmermann.
Additionally, based on the advanced technology platforms of Ingersoll and Zimmermann, Dalian Machine Tool Group integrated technology personnel from the United States and China into a team to develop technology together in order that the technology level and quality of products can meet the international market demand. After the technology digestion, absorption and transfer, the costs were effectively reduced. Besides, Dalian Machine Tool Group developed the products with independent intellectual property rights hereby. So far, Dalian Machine Tool Group has provided domestic and foreign automobile engine manufacturers with flexible manufacturing lines consisting of nearly a hundred of high-speed machining centers.

International technology M \& A not only brought the technology real-time service effect for Dalian Machine Tool Group, but also provided a suitable innovation platform with technology innovation promoting effect to the enterprise. At present, the experts of Dalian Machine Tool Group have developed an advanced dual-axis high speed machining center. In March 2004, Shanghai General Motors Co., Ltd invited bids for high-speed machining centers; Dalian Machine Tool Group conquered Japanese and German rivals to win the bid with advantages in technology and prices, becoming the first Chinese enterprise that cooperated with the leading automobile manufacturer in the world.

International technology $\mathrm{M} \& \mathrm{~A}$ is a strategic issue for enterprises and the success or failure of international technology M \& A is crucial to the survival of enterprises. Also international technology M \& A is often affected by a lot of uncertain factors with huge risks. Therefore, China equipment manufacturers need to research and analyze all the issues including the technology level, technology market and corporate management before they implement international technology M \& A.

\subsection{Technology Development}

1) Acquiring the Technology Related with Core Business.

The goal of international technology $\mathrm{M} \& \mathrm{~A}$ is to make full use of R \& D technology and manufacturing technology of core components for manufacturing enterprises. This requires companies to have definite $M$ \& A strategies, accurately realize their own current technology level, strength and weakness, learn the international advanced technology development trend. Otherwise, they can not improve the core technology, and their technology M \& A will be a failure. Therefore, the acquired technology should be matched with the existing technology level of the enterprises and the acquired technology should also be the core technology of this industry.

2) Focus on the Novelty, Innovation and Applicability of Technology.

The more novel and innovative the technology is, the 
more promising the future development will be, and the more profit the enterprises will obtain. However, the technological progress is just like a double-edged sword. It is detrimental for enterprises to only focus on high technology. Enterprises should consider whether foreign technology is fully compatible with their digestion and absorption capacity, the domestic market and business development goals; and they should pay much attention to the applicability of technology. Enterprises should acquire the technology that can be digested by themselves and help them to improve core competitiveness. Alternatively, they should acquire the technology that facilitates their future development.

3) Attention to Uncertainty of Technology Lifespan.

Technology lifespan is the time interval that the acquired technology in international technology $\mathrm{M} \& \mathrm{~A}$ is substituted by another similar technology in global market. In the global information and electronics industry, there are few successful technology M \& A cases, because this industry develops very quickly and the products update constantly. The lifespan of new technologies and new products may be very short with the fierce competition; the industrial deterioration speed may be much faster than the pace of corporate improvement.

The lifespan of equipment manufacturing technology is relatively long, so it is generally suitable for international technology $\mathrm{M} \& \mathrm{~A}$. When implementing $\mathrm{M} \& \mathrm{~A}$, companies still need to consider whether the efficiency improvement after $\mathrm{M} \& \mathrm{~A}$ is quicker than the technical deterioration speed, after all, not all equipment industry manufacturing technologies have a long lifespan. If the acquired technology is easy to be replaced, then the serious product homogeneity will arise. In the price war triggered by product homogeneity, the profit margin of some companies with large scale is not high, so that their overall operational performance will decline after technology $\mathrm{M} \& \mathrm{~A}$, and even they will be trapped in a more difficult situation due to huge $M \& A$ investment.

\subsection{Technology Market}

1) Making Sufficient Market Research to Reduce Risks Incurred by Information Asymmetry.

Once enterprises determine a target for technology $\mathrm{M}$ \& A, they should conduct sufficient investigation and research, make in-depth analysis and careful judgment. Enterprises may entrust technical appraisers, attorneys, accountants and financial analysts to conduct the research. International technical acquirers are concerned about not only the income statement and balance sheet, but also the technical and operational capabilities of the target company. It is hard to measure these factors, so the sufficient investigation and research are necessary. Through detailed and in-depth investigation and research, enterprises may avoid investment risks and information asymmetry to some extent, achieve the strategic objectives of international technology M \& A.

2) Acquiring the Technology of in Familiar Sectors and Fields.

In general, in international technology $\mathrm{M} \& \mathrm{~A}$, if the acquired technology is a basic technology which is being used after authentication and the acquirers understand technological advantages and potentials of the target companies sufficiently, the risks are relatively low and the return is relatively stable.

If the acquired technology is new and acquirers can not apply it to the existing production process before technology M \& A, however they are familiar with it, and they can obtain relevant technical skills and knowledge through R \& D, know about the technological potentials of the target companies, while the risks are slightly higher. Once technology M \& A is successful, the return is huge.

If the acquired new technology is irrelevant to the core technology of the acquirers, they also do not understand it very well, and they conduct technology M \& A for the sake of diversified development, the risks are much more relatively higher.

\subsection{Company Management}

Two factors influence technology real-time service effect: first, technology level and second, company management. If technology $M$ \& A brings technology real-time service effect, and the new technology and new products meet market demand, then technology M \& A will generate profits and more revenue. Conversely, if M \& A can not bring technology real-time service effect due to the constraints in technology and corporate management, or $\mathrm{M}$ \& A brings technology real-time service effect, however the final products can not meet the market demand, then M \& A will not generate profits. From the perspective of company management, the following aspects should be noticed.

1) Choosing Acquired Technology Matched with the Existing Technology Level.

When a company acquires new technology, it should think over whether the acquired technology is matched with existing technology level of the company. M \& A should not deviate from the current technology level and digestion capacities of the acquirer.

In international technology $\mathrm{M} \& \mathrm{~A}$, an acquirer should evaluate whether the target technology is worth buying with wide application scope. However, due to the limited knowledge and the information asymmetry, the acquirer may make wrong judgment. For example, when a company acquires a medium or small size technology-based company, if the acquired new technology which is in the development stage does not comply with the existing basic technology level, and the acquirer does not have 
enough skills, knowledge and facilities to support the new technology, then the acquirer will be confronted with considerable risks.

2) Considering the Capacity of Integrating Different Corporate Cultures and Human Resources.

For a technology-based company, technology and human resources are the most important factors for the further development. The companies with core resources and personnel advantages always have good prospect and the potentials to seize the considerable market shares. If the company does not have the ability to integrate technology and personnel of the target company efficiently, they may only gain static equipment and products, while technical personnel would leave the company.

It is critical to integrate human resources and corporate cultures In international technology M \& A. Acquirers usually value the technology of the target company, however the technology is developed by talents, so technical personnel are more important for the success of the M \& A strategy. Acquirers should also consider how to integrate all resources harmoniously, for example, how to take over market shares and customers of the acquirees, how to let all employees unite to be a new team, how to eliminate the barriers in different regions, cultures, languages and so on.

Cultural differences cause great challenges to the company management after international technology $\mathrm{M}$ \& A. Every enterprise has its own cultural tradition, which is reflected in distribution system, incentive system, external and internal response mechanisms, resource allocation, management philosophy, technical features, etc. Once any corporate culture forms, it will develop with certain stability and continuity. Therefore, it is a natural reaction that the target companies resist the foreign culture; even if the products and leading technologies of acquirers and acquirees are basically the same, their culture differs significantly. If acquirers can not effectively integrate corporate cultures harmoniously after technology $\mathrm{M} \& \mathrm{~A}$, they will have to face many conflicts and contradictions within their companies, resulting in the low-efficient business operation.

3) Increasing $R$ \& D Investment to Cultivate Independent R \& D Capability.

Enterprises can acquire technology, but they can not purchase R \& D capability. They can introduce management modes, but they can not introduce core competitiveness. They can absorb talents, but they can not attract concepts. After international technology M \& A, enterprises need to increase abundant funds to invest more in key technology and core competencies. Up to now, Chinese equipment manufacturing companies have invested little in technology R \& D. For most companies, their R $\&$ D funds only account for less than $5 \%$ of the total sales revenue.
Without R \& D, enterprises will have no competitiveness in products or the abilities to explore the international market. Most of the Chinese exports are made by low-cost labors with tiny profits. Chinese enterprises often follow the way of technology transfer. If they do not improve themselves by introducing technology, they will not grasp the core technology, brands and sales network with strong competitiveness, even if they have large production scale.

Without R \& D investment and capacity, it is impossible for enterprises to realize self-innovation and development after achieving overseas technology. No matter how to get foreign technology, enterprises should develop new products with independent intellectual property rights, and have independent R \& D ability and innovation system on the basis of technology digestion and absorption. For this purpose, enterprises should increase investment in R \& D. In accordance with the experience of Japanese and South Korean enterprises, only the ratio between introduction fees and digestion fees of a technology is $1: 10$, companies can have self-development capability based on the introduced technology.

Enterprises should combine their own existing technology with the acquired technology in order to maximum effectiveness and control costs to avoid unnecessary risks. At the same time, acquirers should identify and assess the technology of the target company correctly. By reasonable assessment, they should judge whether the value of the technology is enhanced by technology $M$ \& A, in order to avoid losses and minimize $M$ \& A risks.

\section{Conclusion}

International technology M \& A can enable enterprises to access to core technologies and improve the competitiveness for enterprises with technology real-time services effects and technology innovation promoting effects. It will become an important strategy for China equipment manufacturing enterprises to promote innovation and substantial increase in R \& D. However, due to the uncertainty and risks of international technology mergers and acquisitions, enterprises should pay more attention to the technical development, technical marketing and company management to ensure international technology M \& A success and achieve the desired purpose.

\section{REFERENCES}

[1] Y.-J. Lian, “Opinions on Development of Equipment Manufacturing Industry,” Development \& Innovation of Machinery and Electrical Products, Vol. 70, No. 5, 2001, pp. 4-9.

[2] J.-P. Xu and G.-P. Xia, "Research on the International Comparison and Countermeasure of Equipment Manu- 
facturing in China," China Mechanical Engineering, Vol. 19, No. 10, 2008, pp. 2510-2518.

[3] X.-L. Liu, "International Direct Investment and Technology Transfer,” 1st Edition, Economic Science Press, Beijing, 2003.

[4] S. P. Das, “Asymmetric Information, Bargaining, and International Mergers,” Journal of Economics \& Manage- ment Strategy, Vol. 10, No. 4, 2001, pp. 565-590. doi:10.1162/105864001753356105

[5] X.-L. Liu and H.-P. Tan, "Research on the Competitiveness of China Machine Tool from the Perspective of Imports and Exports," Heilongjiang Foreign Economic Relations \& Trade, Vol. 194, No. 8, 2010, pp. 67-69. 